\title{
Comparisons of Vastus Medialis and Vastus Lateralis Muscle Activities according to Different Heights during Drop Landing in Flatfooted Adults
}

\author{
Jong Sung Chang \\ Department of Physical Therapy, Yeungnam University College, Daegu, Republic of Korea
}

\begin{abstract}
Purpose: The purpose of this study was to investigate comparisons of vastus medialis (VMO) and vastus lateralis (VL) muscle activities according to different heights during drop landing in flatfooted adults.

Methods: Fifteen subjects with a flat foot arch and 15 subjects with a normal feet arch were participated. Subjects performed a double limb drop landing task from 20,40, and $60 \mathrm{~cm}$ heights. Surface electromyography was used to measure the muscle activities of the VMO and $\mathrm{VL}$ during drop landing.

Results: There were significant differences of muscle activities in the $\mathrm{VMO}, \mathrm{VL}$, and the $\mathrm{VMO}$ and $\mathrm{VL}$ ratio between groups. The electromyography values of $\mathrm{VMO}, \mathrm{VL}$, and the $\mathrm{VMO}$ and $\mathrm{VL}$ ratio in the normal group were significantly greater than in the flat foot group, and muscle activities and the VMO and VL ratio significantly increased with landing heights in the both groups.

Conclusion: Our results indicated that muscle activity patterns of VOM and VL in the flat foot group were lower at heights than in the normal group, so calf tightness was negative effects on balance and gait ability, so assessment of muscle activation patterns in the knee extensors should be considered during exercise and treatment of flat feet.
\end{abstract}

Keywords: Flat foot, Landing, Vastus medialis, Vastus lateralis

서 론

평발은 진행성이나 후천성으로 목말밑관절과 안쪽 세로활의 정상적 인 역학 손상으로 과도한 엎침이 나타나게 되며, 발목관절과 목말밑 관절 복합체에서 발등쪽굽힘, 벌림, 가쪽번짐의 세가지 형태의 움직 임이 나타난다. ${ }^{1-4}$ 최근에는 목말밑관절의 비정상적인 구조라는 연구 에도 불구하고, 발의 엎침에 대한 정의를 발이 지지면에 접촉하는 표 면적을 증가시키는 발의 움직임으로 정의하였다. 이러한 생역학적인 관점에서 볼 때 발 관절의 다양한 형태가 다리 손상의 내적 위험요소 로 작용하게 되고, 정상적인 발을 가진 대상보다 과도한 엎침 발 자세 는 무릎넙다리 통증증후군(patellofemoral pain syndrome)에 영향을 주게 된다.1.5

무릎넙다리 통증증후군은 일반적인 무릎 손상의 한 형태이며 무 릎넙다리관절의 비정상적인 정렬에 의해 발생하고, 무릎의 앞쪽 통 증을 유발하는 질환이며 주로 젊은 성인에게 많이 나타난다.6-8 이 질
환은 운동을 과도하게 하거나 하지 않았을 때 모두 영향을 받으며 관 절의 직접적인 외상이나 무릎관절 주위의 근육 불균형 등에 의해 발 생하게 된다.6.89 특히 안쪽넓은근(vastus medialis oblique, $\mathrm{VMO}$ )과 가 쪽넓은근(vastus lateralis, $\mathrm{VL}$ )은 무릎넙다리관절의 안정성과 무릎뼈 의 위치를 조절하는 역할을 하게 되며 $\mathrm{VMO}$ 와 $\mathrm{VL}$ 의 근육불균형은 무릎뼈의 부정렬을 일으키고 넙다리 통증을 유발하게 되고. 78,10 무릎 넙다리 통증증후군과 함께 발생하여 발에 나타나는 과도한 엎침의 평발도 다리의 생역학적인 조절에 영향을 주게 된다. 또한 신체 활동 이 많은 젊은 성인으로 인하여 발생하게 되며 일반적인 일상생활활 동보다 충격이 크게 발생하는 점프나 착지 같은 동작에서는 손상의 위험요소가 클 것이다. ${ }^{2111,12}$

착지(landing)는 고강도, 고위험의 운동, 군인들의 활동, 또는 일상 생활활동에서 흔히 나타나며, 착지 시 발생하게 되는 부하를 충분하 게 조절하지 못하면 다리에서 관절, 인대, 근육의 손상, 피로 골절, 연 골 파괴 등이 발생하고, 다리를 따라 척추까지 손상을 일으킨다.12-14
Received Sep 18, 2020 Revised Oct 222020

Accepted Oct 23, 2020

Corresponding author Jong Sung Chang

E-mail changjs@ync.ac.kr
Copylight (C)2020 The Korean Society of Physical Therapy

This is an Open Access article distribute under the terms of the Creative Commons Attribution Non-commercial License (https:// creativecommons.org/license/by-nc/4.o.) which permits unrestricted non-commercial use, distribution, and reproduction in any medium, provided the original work is properly cited. 
그리고 착지는 낙하하는 높이에 따라 몸무게의 10 배 이상의 압력이 다리와 인체에 영향을 주게 되고, 인체의 근육의 활성이 손상을 보호 하게 된다. ${ }^{15,16}$ 또한 다양한 착지 기법으로 무릎 근육의 조절을 통하 여 무릎을 펴기, 조금 굽히기, 완전히 굽히는 자세를 통하여 인체에 주어지는 충격의 양을 조절하고, 발목의 근육 조절로 발등쪽굽힘과 발바닥쪽굽힘을 통하여 발이 바닥에 닿으며 일반적으로 발의 앞쪽 부분이 먼저 닿고 뒤꿈치가 닿는 형태로 체중이 분포된다. ${ }^{4}$

정상 성인이나 평발 대상자가 착지를 수행하는데 있어 높이에 따 른 지면반발력과 다리의 근육활성도에 미치는 영향과 성별, 몸무게, 착지 방법 등이 인체의 손상에 영향을 주는 요소에 대한 연구가 진행 되었다. ${ }^{17,18}$ 그러나 비정상적인 평발은 체중지지 활동에서 무릎의 부 정렬이 함께 연관되어 있지만, 평발 대상자에게 일반적인 스쿼트 운 동이나 보행 외에 착지와 같은 큰 외력이 작용했을 때 넙다리네갈래 근의 작용을 확인하는 연구는 부족하였다. 따라서 본 연구에서는 평 발을 가진 대상자가 착지 시 높이에 따른 안쪽넓은근과 가쪽넓은근 의 근활성도를 측정하여 정상 성인과 비교하고자 하였다.

\section{연구 방법}

\section{1. 연구대상}

본 연구의 대상자는 방사선 검사와 이학적 검사의 결과에 의하여 평 발로 분류된 20대 성인 15 명과 신경학적인 병력이 없고, 근.골격계의 질환 병력이 없는 20 대 정상 성인 15 명을 대상으로 선정하였다. 과제 수행에 영향을 주는 외과적 수술이나 신경학적 병력이 없으며 독립 적인 기립 유지와 착지나 보행 등이 가능한 자를 대상으로 하였다. 모 든 대상자는 연구 참가에 앞서 연구 목적과 방법에 대하여 충분한 설 명을 듣고, 자발적인 동의를 한 후 본 실험에 참여하였다.

\section{2. 실험절차}

지면보다 높은 상자에서 바닥으로 내려오는 착지 과제를 수행하기 위해서 가로 $100 \mathrm{~cm}$, 세로 $50 \mathrm{~cm}$ 의 목재 발판을 임의로 제작하였고, 높이 $20,40,60 \mathrm{~cm}$ 를 무작위로 조절하여 착지 시의 근활성도 분석을 시행하였다. 착지를 위한 자세는 바르게 선 자세에서 양 발을 어깨 너 비만큼 벌린 상태에서 시선은 정면을 바라보고 서 있은 후, 지시에 따 라 바닥으로 거의 동시에 양 발을 딛도록 착지를 하였다. 자연스러운 착지를 위해서 연습을 충분히 시행한 후에 3 회 측정하여 평균값을 분석하였다

\section{3. 측정도구}

\section{1) 평발 검사}

평발 대상자를 구분하기 위해 사용된 발배뼈 하강 검사(navicular drop test)는 부하가 가해지는 동안의 시상면 상의 변화를 나타내는 것으로 발배뼈의 높이를 평가하는데 있어 높은 신뢰도(interclass correlation coefficients (ICC> 0.94)를 가지고 있다.3,19 이 방법은 휴식상태 와 자연스러운 서기 자세에서 발배뼈의 결절의 높이 차이를 평가하 는 것으로 대상자가 무릎을 $90^{\circ}$ 굽힌 상태에서 바닥에 양 발을 가지 런히 놓으며, 체중을 부하 하지 않고 높이를 측정하고, 그 다음 체중 을 완전히 지지하는 서는 자세를 취한 다음 바닥부터 발배뼈의 높이 를 측정한 후 앉은 자세와 선 자세의 차이 값이 발배뼈 하강이 된다. 측정을 하는 동안 측정자 내의 변동성을 최소화하기 위해서 모든 검 사는 동일한 측정자에 의해서 시행하였으며 그룹의 분류는 대상자 의 주로 사용하는 발을 기준으로 3 회 측정하여 평균값을 기준으로 $10 \mathrm{~mm}$ 이상이면 평발로 분류를 하였다. ${ }^{3}$

방사선 검사는 일반적으로 발의 정렬을 측정하기 위해 사용되며, 평발을 평가하기 위해 안쪽 세로활을 주로 이용하여 측정하는 항목 은 Meary 각도(Meary angle, talus-first metatarsal angle), 발꿈치뼈 경사 각도(calcaneal inclination angle), 발꿈치뼈 5번째 발허리뼈 각도(calcaneal-fifth metatarsal angle)이다. Meary 각도는 목말뼈의 긴축과 첫 번 째 발허리뼈 사이의 각도를 측정하여 그 각도가 $4^{\circ}$ 이상인 경우, 발꿈 치뼈 경사 각도는 지면의 수평면과 발꿈치뼈의 발바닥면의 선과 이 루는 각도이며 $18^{\circ}$ 이하인 경우, 발꿈치뼈-5번째 발허리뼈 각도는 다 섯 번째 발허리뼈 몸통의 아래면과 발꿈치뼈의 발바닥면의 선이 만 나는 각도를 측정하여 $170^{\circ}$ 이상이 되는 경우 평발로 분류하였다. ${ }^{20}$

\section{2) 근활성도}

하지의 근활성도를 측정하기 위해 MP150 (Biopac System, USA)을 이 용하며, 전극은 $\mathrm{Ag}-\mathrm{Ag} / \mathrm{Cl}$ (Biopac, diameter $2 \mathrm{~cm}$ ) 표면 전극을 사용하 여 부착하였다. 측정하기 전 피부 저항을 최소화하기 위하여 전극 부 착 부위를 면도한 후 알코올로 닦아내고, 전극 부착 부위가 완전히 마른 후에 전해질 겔이 도포된 두 개의 활성전극과 접지전극을 피부 에 부착한다. 부착하는 근육의 부위는 안쪽넓은근의 경우 넙다리의 장축으로 $50^{\circ}$ 무릎뼈의 위안쪽 $4 \mathrm{~cm}$ 되는 위치에 부착하고, 가쪽넓은 근의 경우 중앙선을 기준으로 가쪽 $15^{\circ}$ 대각선 방향으로 무릎뼈의 위 가쪽 $10 \mathrm{~cm}$ 위치에 부착하였다.

근전도 신호는 생체 신호에 대한 아날로그 신호를 디지털화 하여 표본추출률(sampling rate) $1,000 \mathrm{~Hz}$ 로 수집하였고, 자료 처리는 Acqknowledge 3.8.1 (Biopac System, USA) 소프트웨어를 사용하여 30-500 $\mathrm{Hz}$ 에서 구간 필터링을 하고 잡음제거를 위해 $60 \mathrm{~Hz}$ 로 notch 필터링하 고, 완파정류(full-wave rectification)를 시행 후 실효치값(root mean square, RMS)을 이용하였다. 그 후 최대 등척성근수축(MVIC)값으로 나누어 백분율로 환산한 값인 \%MVC 값을 사용하는 방법을 이용하 여 착지 시 근전도 신호를 정량화하였다. 


\section{4. 자료분석}

본 연구에서 수집된 자료는 SPSS 18.0 for Windows 프로그램을 이용 하였고, 모든 자료는 Shapiro-Wilk 검정을 통하여 정규성 검정을 하였 다. 대상자의 일반적 특성은 기술통계로 분석을 하였으며, 착지 시 그 룹과 높이에 따른 근활성도를 비교하기 위해 이요인반복측정(twoway repeated measures)을 사용하였고, 그룹 간 비교를 위해 독립표본 $\mathrm{t}$-검정을 이용하였으며, 통계학적 유의성을 검정하기 위해 유의수준 $\alpha$ 는 0.05 로 하였다.

\section{결 과}

\section{1. 일반적 특성}

본 연구에 참여한 대상자는 평발 대상자가 15 명, 정상 성인 15 명으로 총 30 명으로 구성되어 있다. Table 1에 제시되어 있는 것처럼 성별, 나 이, 키, 몸무게는 두 그룹 간 차이가 없었다 $(\mathrm{p}>0.05)$. 그러나 발배뼈 하 강 거리에서 평발대상자가 정상 성인보다 더 크게 나타났다 $(\mathrm{p}<0.05)$.

\section{2. 근활성도 비교}

안쪽넓은근, 가쪽넓은근 및 안쪽넓은근과 가쪽넓은근의 비율에서 착지의 높이에 따라 평발 대상자와 정상 성인 사이의 근활성도는 유 의한 차이가 나타났으며 $(\mathrm{p}<0.05)($ Table 2$)$, 평발 대상자보다 정상 성인 에서 더 높은 근활성도를 보였다. 안쪽넓은근은 $40 \mathrm{~cm}$ 와 $60 \mathrm{~cm}$ 에서,

Table 1. General characteristics of subjects

$(n=30)$

\begin{tabular}{lccc}
\hline & Flat feet & Normal feet & $p$ \\
\hline Gender (M/F) & $8 / 7$ & $8 / 7$ & \\
Age (yr) & $23.8 \pm 3.6$ & $23.2 \pm 2.8$ & 0.62 \\
Height (cm) & $168.5 \pm 8.3$ & $169.2 \pm 7.6$ & 0.80 \\
Weight (kg) & $62.5 \pm 9.6$ & $61.7 \pm 8.9$ & 0.66 \\
Navicular drop (mm) & $12.8 \pm 2.5$ & $6.2 \pm 1.4$ & $<0.001^{*}$ \\
\hline
\end{tabular}

가쪽넓은근은 $20 \mathrm{~cm}$ 와 $60 \mathrm{~cm}$, 안쪽넓은근과 가쪽넓은근의 비율은 $40 \mathrm{~cm}$ 와 $60 \mathrm{~cm}$ 에서 그룹 간의 차이를 보였다. 그리고 착지 높이에 따 라 두 근육의 근활성도 및 안쪽넓은근과 가쪽넓은근의 비율이 유의 한 차이가 나타났으며, 안쪽넓은근의 근활성도에서 높이와 그룹 간 의 상호작용이 나타났다 $(\mathrm{p}<0.05)($ Table 2$)$.

\section{고 찰}

높은 위치에서 바닥으로 착지를 하는 것은 평발 대상자에게 골절이 나 손상을 일으키는 위험한 요소이고, 충격흡수를 하기 위한 자세조 절 및 전략이 떨어진다. 2,11,12 이러한 평발과 무릎넙다리 통증증후군 은 많은 연관성을 가지고 있으며 발목의 조절과 함께 무릎관절의 조 절을 함께 확인해야 한다. 본 연구는 평발을 가진 대상자에서 20,40 , $60 \mathrm{~cm}$ 의 높이에서 착지 시 높이에 따른 안쪽넓은근과 가쪽넓은근의 근활성도를 비교하였다. 연구의 주요 결과는 안쪽넓은근, 가쪽넓은 근 및 안쪽넓은근과 가쪽넓은근의 비율에서 착지의 높이에 따라 평 발 대상자의 근활성도가 정상 성인보다 낮게 나타났으며, 높이에 따 라 두 그룹 모두에서 근활성도가 유의하게 증가하였다. 이는 외부로 부터 발생하는 힘에 대해 반응하는데 있어서 높이의 증가로 인한 외 력의 증가로 두 근육의 근활성도가 높아지며 자세조절을 하게 되고, 그룹 간의 근활성도 차이가 무릎관절을 조절하고 충격을 흡수하는 데 있어 평발 대상자가 정상 성인보다 부족한 것으로 확인되었다. ${ }^{2}$

일상생활활동에서 반복적인 강한 외력은 조직 손상을 유발하고 수행 능력을 감소시키고, 착지와 같은 동작은 높이에 따라 차이가 있 지만 신체 무게의 2-11배 정도의 충격을 발생시켜 신체의 손상을 크 게 일으키게 된다. ${ }^{15,16}$ 이러한 충격을 흡수하는 방법으로 착지를 할 때 적절한 다리 근육의 조절이 필요하다. 자세조절에서 일차적으로 발목의 근육 조절에 의해 충격 흡수와 발의 안정성을 제공해 주게 되 고, 무릎 주위 근육의 근활성도 증가를 통해 신체 손상을 예방하게

Table 2. Muscle activities of VMO and VL at different landing heights

\begin{tabular}{|c|c|c|c|c|c|c|}
\hline & Landing height & Flat feet & Normal feet & Landing height & Group & Interaction \\
\hline \multirow[t]{3}{*}{ VMO } & 20 & $24.40 \pm 2.30$ & $24.80 \pm 2.54$ & $<0.001^{*}$ & $<0.001^{*}$ & $<0.001^{*}$ \\
\hline & $40^{+}$ & $26.33 \pm 3.22$ & $28.91 \pm 3.57$ & & & \\
\hline & $60^{+}$ & $30.87 \pm 4.34$ & $36.93 \pm 3.67$ & & & \\
\hline \multirow[t]{3}{*}{ VL } & $20^{+}$ & $26.73 \pm 2.40$ & $26.87 \pm 2.13$ & $<0.001^{*}$ & $0.04^{*}$ & 0.06 \\
\hline & 40 & $29.40 \pm 4.15$ & $30.67 \pm 3.77$ & & & \\
\hline & $60^{+}$ & $33.40 \pm 3.72$ & $37.53 \pm 4.42$ & & & \\
\hline \multirow[t]{3}{*}{ VMO:VL } & 20 & $91.37 \pm 5.34$ & $92.43 \pm 7.57$ & $0.04^{*}$ & $<0.001^{*}$ & 0.22 \\
\hline & $40^{+}$ & $89.91 \pm 5.27$ & $94.40 \pm 4.58$ & & & \\
\hline & $60^{+}$ & $92.34 \pm 6.64$ & $98.71 \pm 5.02$ & & & \\
\hline
\end{tabular}

All data are reported as mean \pm standard deviation.

VMO: vastus medialis obligue, VL: vastus lateralis, VMO:VL: ratio of VMO \& VL.

The asterisk $(*)$ indicates the use of repeated measures two factor analysis and significance at the $p<0.05$ level, The cross $\left(^{+}\right)$indicates the use of the independent $t$-test and significance at the $p<0.05$ level. 
된다..$^{11,12,14}$ 본 연구에서 평발 대상자보다 정상 성인에서 안쪽넓은근 과 가쪽넓은근의 근활성도가 높았으며, 특히 높이가 높아질수록 근 활성도가 유의한 차이를 보였다. 이는 평발은 발에서의 충격 흡수가 부족할 뿐만 아니라 편심성 수축으로 무릎관절을 조절하는 무릎관 절 폄근의 근활성도에도 영향을 미치는 것이다. Chang 등의 연구에 서 높이가 높은 곳에서 착지를 할 경우 평발 대상자는 무릎의 굽힘 각도가 더 크게 나타났는데도 불구하고 지면반발력이 증가하는 결 과를 보였다.

두 그룹에서 높이가 증가함에 따라 안쪽넓은근과 가쪽넓은근의 근활성도가 증가하는 것은 외부 부하로 발생하는 충격으로부터 인 체를 보호하기 위한 기전으로 일반적으로 무릎의 각도가 증가되거 나 넙다리네갈래근의 근활성도가 증가되었다. 이는 부하의 크기가 점점 증가할수록 근활성도가 증가하는 이전 연구와 동일하게 나타 났으며, $7,10,21,22$ 효과적인 근육 동원을 위해서 근력 강화가 필요할 것으 로 생각되고, 특히 짧은 기간 동안 근육 조절로 이루어지는 착지 등의 순발력을 요구하는 동작은 반복하는 훈련을 통하여 기능적으로 효 율적으로 근활성이 가능하도록 해야 할 것이다.

Herrington과 Pearson ${ }^{21}$ 은 정상성인을 대상으로 다리에 부하가 커 질수록 안쪽넓은근과 가쪽넓은근의 근수축 비율이 증가하였으며, 두 근육 간의 근수축 타이밍 시간에는 차이가 나지는 않는다고 하였 다. 또한 무릎관절의 각도나 엉덩관절의 위치에 따라 근활성도 비율 의 차이가 나타나는데 근력 강화나 훈련을 할 때 적절한 자세를 선택 적으로 할 수 있다.6,79,10,22 본 연구에는 평발 대상자에서 안쪽넓은근 과 가쪽넓은근의 비율이 정상에 비해 낮게 나타났으며, 두 그룹 모두 높이가 증가함에 따라 비율이 높아지는 것을 확인하였다. 이는 무릎 조절을 정상적으로 하기 위해서 안쪽넓은근이 적절한 타이밍에 적절 한 강도로 수축을 해야 자세조절을 잘 할 수 있을 것이다. 무릎넙다 리 통증증후군, 무릎관절의 부정렬, 하이힐 착용이나 발목관절에 문 제가 있는 대상자는 근수축 비율에 차이가 나거나 안쪽넓은근의 근 수축 개시 시간의 지연 등이 나타나게 되었다.6,8,9,23 이러한 문제를 중 재하기 위해 다리의 다양한 상황을 고려한 근력 강화 프로그램이 제 시되어야 할 것이다.

평발은 보행이나 착지 등의 일상생활활동에서 작용하는 충격을 흡수하는데 어려움이 발생하게 되며, 그 외력의 크기가 클수록 인체 에 전해지는 충격이 커지거나 자세조절에 어려움을 갖게 되는 것을 알 수 있으며, 본 연구에서 연구에 참여한 대상자가 적고 다양한 근 육을 비교하지 못하여 다양한 분석이 부족한 것은 다리의 다양한 근 육의 근활성도 평가, 적절한 운동 과제 및 생역학적 평가도구를 이용 한 연구가 필요할 것으로 판단된다.

평발의 평가와 치료가 일반적으로 발 주위 근육에 초점을 맞추어 판단을 하게 되는데 본 연구에서는 평발에 의해 발생하게 되는 무릎
관절을 조절하는 넙다리네갈래근 중 안쪽넓은근과 가쪽넓은근의 근활성도 확인을 통해 안쪽넓은근과 가쪽넓은근의 근육 조절에 문 제가 있는 것을 확인하였고, 이에 따라 임상에서 평발 대상자의 근력 강화에 무릎관절 주위 근육에 대한 관심이 필요하고, 스쿼트 자세나 각도, 엉덩관절의 회전 정도, 안쪽넓은근의 근수축 지연 또는 약화를 조절할 수 있는 적절한 평가나 중재에 대한 연구가 이루어져야 할 것 으로 생각된다.

\section{REFERENCES}

1. Ashnagar Z, Hadian MR, Olyaei G et al. Ultrasound evaluation of the quadriceps muscles in pronated foot posture. Foot (Edinb). 2019;38:8690.

2. Chang JS, Kwon YH, Kim CS et al. Differences of ground reaction forces and kinematics of lower extremity according to landing height between flat and normal feet. J Back Musculoskelet Rehabil. 2012;25(1):21-6.

3. Cote KP, Brunet ME, Gansneder BM et al. Effects of pronated and supinated foot postures on static and dynamic postural stability. J Athl Train. 2005;40(1):41-6.

4. Hargrave MD, Carcia CR, Gansneder BM et al. Subtalar pronation does not influence impact forces or rate of loading during a single-leg landing. J Athl Train. 2003;38(1):18-23.

5. Barton CJ, Bonanno D, Levinger P et al. Foot and ankle characteristics in patellofemoral pain syndrome: A case control and reliability study. J Orthop Sports Phys Ther. 2010;40(5):286-96.

6. Chang WD, Huang WS, Lai PT. Muscle activation of vastus medialis oblique and vastus lateralis in sling-based exercises in patients with patellofemoral pain syndrome: A cross-over study. Evid Based Complement Alternat Med. 2015;2015:1-8.

7. Chen S, Chang WD, Wu JY et al. Electromyographic analysis of hip and knee muscles during specific exercise movements in females with patellofemoral pain syndrome: An observational study. Medicine. 2018;97 (28):e11424.

8. Park S, Lee WJ, Park JW. Differences of onset timing between vastus medialis and lateralis during knee isometric contraction on individuals with genu varum or valgum. J Kor Phys Ther. 2014;26(1):9-14.

9. Seo JH, Chang JS, Lee MY. Effects of squatting with different foot positions on muscle activations in subjects with genu varum. J Kor Phys Ther. 2019;31(2):76-81.

10. Jeon IC. Comparison of muscle activity of vastus lateralis and medialis oblique among knee extension angles at $90^{\circ}, 135^{\circ}, 180^{\circ}$ in sitting position. J Kor Phys Ther. 2020;32(1):52-7.

11. Walsh M, Boling MC, McGrath M et al. Lower extremity muscle activation and knee flexion during a jump-landing task. J Athl Train. 2012;47 (4):406-13.

12. Yeow CH, Lee PV, Goh JC. Regression relationships of landing height with ground reaction forces, knee flexion angles, angular velocities and joint powers during double-leg landing. Knee. 2009;16(5):381-6.

13. Blackburn JT, Padua DA. Sagittal-plane trunk position, landing forces, and quadriceps electromyographic activity. J Athl Train. 2009;44(2):174-9. 14. Yeow CH, Lee PV, Goh JC. Effect of landing height on frontal plane ki- 
nematics, kinetics and energy dissipation at lower extremity joints. J Biomech. 2009;42(12):1967-73.

15. Kulas A, Zalewski P, Hortobagyi T et al. Effects of added trunk load and corresponding trunk position adaptations on lower extremity biomechanics during drop-landings. J Biomech. 2008;41(1):180-5.

16. Zhang SN, Bates BT, Dufek JS. Contributions of lower extremity joints to energy dissipation during landings. Med Sci Sports Exerc. 2000;32 (4):812-9.

17. Decker MJ, Torry MR, Wyland DJ et al. Gender differences in lower extremity kinematics, kinetics and energy absorption during landing. Clin Biomech. 2003;18(7):662-9.

18. Kernozek TW, Torry MR, Vanh H et al. Gender differences in frontal and sagittal plane biomechanics during drop landings. Med Sci Sports Exerc. 2005;37(6):1003-12.

19. Vicenzino B, Griffiths SR, Griffiths LA et al. Effect of antipronation tape and temporary orthotic on vertical navicular height before and after exercise. J Orthop Sports Phys Ther. 2000;30(6):333-9.

20. Flores DV, Mejia Gomez C, Fernandez Hernando M et al. Adult acquired flatfoot deformity: Anatomy, biomechanics, staging, and imaging findings. Radiographics. 2019;39(5):1437-60.

21. Herrington L, Pearson S. Does level of load affect relative activation levels of vastus medialis oblique and vastus laterialis?. J Electromyogr Kinesiol. 2006;16(4):379-83.

22. Kim MK, Ji HJ, Kong YS et al. Comparative study on muscle activity and torque value of quadriceps of healthy adults. J Kor Phys Ther. 2016; 28(3):212-6.

23. Kim HH, Song CH. Effects of shoe heel height on the onset of vmo relative to $\mathrm{vl}$ and $\mathrm{vmo} / \mathrm{vl}$ emg ratio during stair ascent in women without knee pathology. J Kor Soc Phys Med. 2011;6(2):135-43. 